\title{
Cognition and Conflation: Addressing a paradox in cognitive linguistics
}

I describe a key implication of cognitive linguistics that has been ignored or undertheorized. At the center of metaphors and blends, I argue, is an act of conflation, in which abstract meaning is thought in or as a concrete form. Cognitive linguistics asserts this key fact but has failed to theorize explicitly about 1) abstract meaning and 2) its conflation with concrete domains. I examine the role of abstract domains in cognition and suggest ways that the conflation of abstract and concrete domains can be addressed from a cognitive perspective.

\section{Preamble}

Scientific theories go astray when they lose sight of the very phenomena they are intended to explain. A theoretical explanation or "map" is helpful only if one also possesses accurate knowledge of the "territory" itself. For cognitive science, the territory is the rich semantics of lived meaning, cognition as it is experienced. In this essay I argue that two of the main schools of cognitive linguistics, Lakoff's and Johnson's metaphor theory and Fauconnier's and Turner's blending theory, have neglected some key dimensions of actual, lived cognition. Both schools, as I see it, have been too eager to develop theories to explain cognition without obtaining a sufficient description of cognitive life itself. By performing such descriptions, I show, we confront a paradox at the heart of human thought. ${ }^{1}$

1 This paper addresses metaphors and blends but views these as nearly ubiquitous in, and central to, human cognition. Any general theory of human cognition and meaning-making must address these phenomena as central factors. For the sake of simplicity, then, I will merely use the broader term "cognition" when referring to these complex cognitive acts. 


\section{Introduction: a Paradox}

Cognitive linguistics has revclutionized the study of cognition by revealing the intimate connections between abstract thinking and concrete patterns of meaning. In opposition to theories that view cognition in terms of pure concepts, a priori rules, or formal algorithms, cognitive linguistics has revealed the active influence of many "impure" factors - e.g., concrete perceptual patterns, image schemas, motor schemas, and cultural frames - in the very work of abstract reasoning. The two theories I shall discuss, metaphor theory and blending theory, have developed sophisticated accounts of the mechanisms by which such cognition is produced. However, in their zeal to give concrete, embodied domains their due within cognition, both schools have avoided some central, perplexing features of the very metaphors and blends they champion. In this essay I explore one of these features, which forms a paradox at the heart of cognition, and I offer some suggestions for integrating it into a cognitive perspective on meaning.

The paradox in these cognitive accounts is this: the very acts by which abstract thinking establishes meaning are acts of "domain confusion", or conflation. Whether we are examining metaphors or blends, meaning is generated by mixing and conflating different domains, taking one thing to be another kind of thing, and transgressing the very semantic boundaries that, upon reflection, separate domains. To think metaphorically, as Lakoff and Johnson have emphasized, is to think the abstract in the concrete, in the specific structure of some concrete pattern or image, which lends its concrete entailments to the abstract domain. This kind of thinking involves no superficial comparison between domains, as earlier theories of metaphor claimed; instead, concrete forms somehow take on conceptual significance. Similarly, blending theory argues that abstract cognition is a matter of constructing "mental spaces", virtual scenarios whose specific structures and dynamics allow abstract meaning to be played out in concrete terms. Both theories assert that we do not think directly about abstract meanings but instead think out abstract issues through concrete images and patterns - whether this thinking involves the repetition of perceptual patterns, as metaphor theory asserts, or the creative construction of new patterns, as blending theory claims. In either case, the very 
act of meaning-making blurs distinctions, actively transgresses semantic domains, and leads us to identify the meaning of one thing with ... something else. ${ }^{2}$

The paradox, then, is that cognition achieves clarity, understanding, and comprehension through processes of conflation and confusion that would seem to undermine clear thinking. How is it, we must ask, that blurring differences, blending elements, and actively treating distinct domains as one domain can produce clear meaning and stable knowledge? This paradox is, I will argue, an ineliminable aspect of metaphors and blends - and is therefore an issue that any cognitive theory must address.

It might seem that metaphor theory and blending theory have already addressed such conflation in their detailed accounts of the processes operating in and behind cognition. In fact, however, one finds little explicit discussion in either theory of 1) abstract meaning or of 2) its conflation with concrete forms. Recall that in its early manifestations cognitive linguistics challenged theories that gave abstract concepts too much credit for cognition, i.e., theories that treated cognition as driven by pure, a priori, or transcendent concepts, to the exclusion of concrete factors. ${ }^{3}$ Nonetheless, after dismantling such "objectivist" theories by demonstrating the central role of concrete meanings in cognition, cognitive linguistics has not supplied a theory of abstract meaning, or an account of the role of abstract meaning in cognition. Instead, it has focused on what may be called the mechanics of concrete meaning, i.e., the ways concrete source domains contribute to metaphors or blends. These are crucial contributions, but as I shall argue, concrete patterns do not exhaust cognition, because cognition contains an ineliminably abstract dimension. Although they are perhaps difficult to identify in the midst of the concrete forms that populate our thinking, abstract domains are nonetheless real and important aspects of the "territory" of cognition. Hence an account of cognition is incomplete until it addresses 1) the presence of abstract domains in cognition, and 2) the key question of how abstract domains engage concrete patterns (via conflation, I will argue) to produce meaningful thinking. Before turning to an account of conflation, then, we must examine the issue of abstract meaning in cognition.

2 My use of the term "meaning" is phenomenological. That is, anything that can be brought to our awareness has meaning, although I view awareness as a matter of shared, public experience, not purely private introspection. Many habits and other factors act on experience at the subconscious level, but they have meaning insofar as they can be experienced and examined consciously, with reference to publicly shared norms.

3 Cf. Lakoff \& Johnson (1980), Chapter 25, "The Myths of Objectivism and Subjectivism", and Johnson (1987), "Introduction". 


\section{On Abstract Domains}

I have said that the central insight of cognitive linguistics is the intimate relationship between abstract and concrete meanings - in particular, the dependence of the abstract on the concrete. Because of this very claim of dependence, however, these two terms take on problematic meanings. What I mean by concrete is anything with a specific, identifiable character derived from its being - in principle - perceivable. ${ }^{4}$ Such meanings occur at two levels, broadly speaking: 1) Actual objects, events, or patterns we perceive, feel, encounter, etc., and 2) Imagined objects, events, actions, feelings, etc. On this view, the rock $I$ hold in my hand has a concrete meaning, as does the dynamic pattern of my throwing it into the canyon and observing its path. Their meanings refer to their perceivable, sensible features, e.g. color, weight, distance, speed. Likewise, the mental images of a rock and of its being thrown have concrete meanings, because they have a specific character that is identifiable in sensible terms. Ultimately, their meaning is given as specifications of such perceivable features. It is these latter, imagined meanings that are normally taken up by abstract cognition to help play out its meaning and logic..$^{5}$ (In contrast, art and ritual are two kinds of cognitive activities that often return cognition to the actual things perceived, playing out their abstract meanings in and through these elements.)

By abstract I mean more general notions that are not bound to specific, concrete elements or images. Love, friendship, justice, understanding, piety, etc., are some of the classical ideas that philosophers have identified as essentially abstract. Put simply, whenever we are dealing with interpersonal, social, political, or intellectual issues, we are dealing with abstract domains. Many aspects of science are also abstract, e.g., its formal symbolism, but the natural sciences have as their goal the description of non-personal, concrete events, and thus ultimately imagine their subject matter concretely. The social sciences, on the other hand, must grapple with many concepts, norms, ideas, and values that cannot be reduced to concrete levels of meaning. The firings of neurons, the movements of bodies, and the material conditions of social life do not fully account for the ways people value democracy, for example. As the concept of a better form of life, i.e., as a norm that expresses an ideal beyond actual facts, democracy involves abstract norms. Such norms must therefore be included in any social science dealing with democracy. Similarly, most of the

4 I use the term perceivable in the broad sense of anything that can be observed, felt, or sensed.

5 Johnson (1987) gives the best account of such image schemas. 
actual problems and issues we confront in everyday life refer to abstract domains; although the individuals and settings are concrete, the issues we struggle to grasp are abstract.

Abstract ideas play a significant but elusive role in our thinking. We often use abstract words habitually, without much reflection. They come easily to us and populate our thinking and speech seamlessly. It is only through later reflection or analysis that we realize that these familiar words are difficult to specify and define. Once we attend to them directly, they seem vague, extremely remote from concrete experience, and elusive. (Recall Augustine on time: "What then is time? If no one asks me, I know what it is. If I wish to explain it to him who asks, I do not know".) Nonetheless, we find such ideas to be crucial to experience, because they serve as norms for understanding our lives. With an erroneous sense of justice, we learn, one can make serious errors in judgment and cause great harm. Thus we need norms that are true (an idea which itself proves elusive to reflection) and which work well. And, when we realize reflectively that some norms already influence our thinking, we are compelled at times to examine our norms carefully. But, as any reader of Plato's dialogues can attest, approaching the ideas of justice, piety, friendship, or love directly proves extremely difficult! Secondly, abstract ideas can approach extreme generality, thus transcending all concrete meanings. Such generality promises a "universal" standard by which we can potentially understand and assess many specific situations. However, we struggle to say what these ideas are - what they mean in themselves - and our thinking easily loses its moorings at this level of abstraction.

In order to be reminded of the different ways abstract domains influence cognition, let us briefly describe three familiar cognitive experiences. First, there is the experience of thinking effortlessly, habitually, in the midst of a situation. For example, in the midst of an office dispute among colleagues, we might try to balance their various needs and concerns. Our thinking is habitual to the extent that we do not focus on balance as one way of addressing the problem; it simply is the way to address it. The office situation is not understood separately from the schema of balance, with its particular logic; the situation is seen through this schema, or source domain, from the start, and we use the schema's concrete dynamics to play out and address the problem. Such habitual 
cognition has been the primary focus of metaphor theory, which is interested in the role of entrenched source domains in shaping and constraining thought. ${ }^{6}$

Second, there is the experience of struggling to understand a situation in order to address some problem or question. Faced with conflicts in the office, I hesitate to apply any particular schema to it. I am not sure that I have the proper schema or source domain for understanding what is happening, and I seek one that will work. I may ask: "Is this a case of an imbalance of equally valid needs, of a transgression of duties, of a clash between strong and weak personalities, or a case of emotional attractions and repulsions?" Whereas in habitual cognition I merely think with some schema, in "problematic" cognition I become aware that I have ways of interpreting the situation, some of which may be more helpful than others. And, crucially, I become aware that the situation I am trying to deal with is more than - i.e., its meaning transcends - any schema I may apply to it. A schema may help, but it does not exhaust the situation's meaning. The cognitive effort in this case involves finding a good match between the situation and the various schemas or patterns I may apply to it. Of course, I may eventually choose to use the familiar schema of balance to interpret and "run" the situation, but the experience of such "problematic" cognition is very different from unreflective, habitual cognition. ${ }^{7}$ It opens up several new dimensions of meaning that are available to me, including the awareness that I have the capacity for thought beyond habitual, schema-based cognition.

Third, there is the experience of focused abstraction, of suspending concern with particular situations and evaluating the schemas available to cognition as such. A famous example is Plato's Republic, which contains many moments when Socrates, aware of the various schemas his society uses for the idea of justice, asks whether these patterns are accurate, right, or true. That is, he examines the general ideas that somehow provide our sense of justice, those ideas by which we can say that an act or situation is or is not just (even if, as Plato shows, we cannot strictly define what justice is). This is not an unusual cognitive experience. It happens whenever we assert that some particular way of

6 Cf. Adamson (2005) for a discussion of the limits of this approach, which interprets cognition as unconscious, rather than as habitual. I argue that any theon of meaning must ultimately appeal to what we can experience consciously, in order to have clear insight into what one is explaining.

7 This point is often lost, I think, in metaphor theor. Presented with language that employs conventional metaphors, metaphor theory treats this usage as a function of the cognitive unconscious, when in fact it may be the result of conscious problem-solving, in which we seek a fit between schemas and situations. By attending more closely to different cognitive experiences, we see that each type of experience requires different theoretical explanations. 
thinking about justice is erroneous, e.g. "I know that is how our society sees justice, but that does not make it right or true". Notice that such an assertion is not a challenge at the level of a particular schema ("You are not balancing these needs correctly") or a dispute among schemas ("Justice is not about balancing; it is about harmony'). Instead, it is the experience of evaluating all schemas for justice according to some more general sense of justice. Such cognition achieves a level of genuine abstraction, beyond any particular way the idea may be "shown" or applied. I take this experience to be cognitively real and repeatable, in the sense that it is an identifiable kind of thinking, different from the first two outlined above. There is a distinct difference between thinking habitually with schemas, thinking problematically about bow a schema fits a situation, and thinking about a general idea which can guide our evaluation of all possible schemas.

Now, I am aware that cognitive linguistics is generally wary of any objectivist or "metaphysical" interpretations of such ideas, and that its great insight lies in revealing the intimate dependence of abstract ideas on concrete patterns of meaning. Nonetheless, a brief examination of the experiences above will show that 1) no transcendent interpretation of ideas is necessary and 2) abstract meaning is a real, significant feature of cognition that cannot be reduced to or replaced by the concrete patterns that also populate cognition. As a central aspect of the actual "territory" of cognition - even in its embodied, concrete manifestations - abstract meaning and ideas must be taken seriously. First, the reflective experience of trying to understand general ideas, or of judging schemas in terms of abstract ideas, explicitly focuses on meanings beyond particular situations. In such experiences, we are not thinking about particular situations but rather about the general ways we might understand any situation like them. True, the particular language we use to work out our thinking almost always contains concrete patterns of meaning, e.g., metaphors and blends. ${ }^{8}$ Nonetheless, our thinking is not about such patterns - it is about the general meaning of justice, friendship, or morality, which we hope to use as a norm for judging many different situations.9 Second, to recognize this capacity for

8 For a survey of metaphors used in classical philosophical theories, see Lakoff \& Johnson (1998), Part II.

9 Thus Plato seeks to define the idea of justice, recognizing that the patterns of meaning he has inherited may or may not be accurate representations of this idea. When we find him saying that justice is "the harmony of the whole, as each part contributes its unique function to serve the good of the whole", we must distinguish between his actual subject, which is the idea of justice, and the specific way it is articulated in this blend. The language masks this 
abstraction is not to give ideas a metaphysical, objective existence beyond thinking (although it does not rule this out, either). Instead, it is to recognize a genuine achievement of thought, that of suspending concern with particularity and seeking meaning at the most abstract, general levels. We can, and do, achieve this level of cognition, even if we doubt that such ideas have a referent in a mind-independent reality.

In sum, cognition is very often about some abstract issue, even though we use concrete patterns of meaning to "run" the implications of our thinking. The concrete pattern, although present in abstract thought, is not the actual object of our thinking, but rather provides specific forms for "fleshing out" our thoughts about abstract issues. In one sense, the concrete "hides" itself from our attention, even as it provides the means of cognition. We are often not aware of the concrete domains that we use to think more abstractly. Conversely, the abstract does not appear directly but takes its place and locates its meaning within the concrete structures that "represent" it in thought. In addition, we can see that cognition has the ability to transcend particular forms and to seek understanding at very general levels. We appeal to these ideas, for example, when we question the very schemas we have inherited in order to find schemas that are closer to the "idea itself". When examined directly, however, these general ideas do not provide a specifiable, positive meaning that can be grasped fully. Finally, then, if cognition is about abstract issues, requiring us to think beyond the limits of specific, concrete forms, then it is not sufficient in our theories to explicate only those concrete forms that support cognition. We must examine abstract meaning and the relationship between abstract domains and concrete forms in order to establish a comprehensive account of cognition.

\section{On Conflation}

If, from a cognitive perspective, we recognize the crucial presence of both abstract domains and concrete forms in cognition, we are drawn to the following conclusion: metaphors and blends are acts of cognition in which abstract meaning is conflated with concrete forms. Abstract problems and issues do not play out in purely abstract terms but instead take on a concrete character, i.e., as the abstract problem is conflated with a specific concrete

difference, of course, but the difference is evident in the experience of tbinking uith Socrates, i.e., when we explicitly distinguish the object of our thinking, an abstract idea, from the ways it is articulated in any specific thought. 
scenario (whether a familiar source domain or a novel blend). As we have seen, the presence of concrete forms does not remove or replace the abstract dimension of thought, since we are still thinking about the abstract question or issue, and not the specific form. Even as we seek concrete forms with which to reason, we are also focused on the more general, abstract meaning that tells us that some forms are better than others. Therefore, our accounts of concrete forms and their entailments cannot exhaust our account of cognition. Nonetheless, paradoxically, it is in these schemas or patterns that the abstract issue comes to be known; and it is in the conflation (not merely association) of abstract and concrete domains that cognition does its work. In the next section, I outline some of the key features of any cognitive theory that would address the conflation at the heart of cognition. First, though, let us briefly examine the issue of conflation in metaphor theory and blending theory.

\section{Conflation in Metaphor Theory}

The notion of conflation appears explicitly in Lakoff's and Johnson's Pbilosopby in the Flesh (1998: 46ff). Building on the work of Joe Grady and Christopher Johnson, they argue that the first stage of cognitive development involves the conflation of various domains to establish "primary metaphors". These primary metaphors emerge "automatically and unconsciously" as we experience various concrete and "subjective" events together, e.g., feeling warm while being held, discomfort when lifting heavy objects, getting information through vision, etc. Lakoff and Johnson, building on Grady's work, posit that "Early conflations in everyday experience should lead to the automatic formation of hundreds of primary metaphors that pair subjective experience and judgment with sensorimotor experience" (ibid: 49). Further, the complex, mature metaphors we find at work in scientific theories, literature, politics, etc., are "built out of primary metaphors" (ibid: 60). Thus primary metaphors are always at work, either directly or indirectly, in shaping cognition. Soon, however, there is posited a second stage of development, "differentiation", in which we recognize these conflated domains as different, thus separating them conceptually (ibid: 46). After this, we can distinguish these two domains in reflection, but, according to Lakoff and Johnson, our everyday cognition continues to depend on primary metaphors and on various extensions of them, mostly in the form of unconscious, neural activation.

Two sets of questions arise from this account. First, why are the primary metaphors alone instances of conflation? In what sense should they be 
considered conflations, if other metaphors are not? If conflation is a matter of understanding one domain as another, and of taking it to be this or that form, then are not all metaphors - especially the deeply entrenched "conceptual metaphors" Lakoff and Johnson describe - conflations? If, instead, it is the relatively unreflective or unconscious character of early development that marks it as conflationary, would this not also be the case for the great majority of metaphors, which, the theory asserts, are also used unreflectively?'1" In either case, the theory does not explain why some metaphors are conflations and others are not. Second, why does conflation disappear from the analysis of metaphorical cognition, if these primary metaphors provide many of the building blocks for later cognitive development? In using these primary metaphors again, either directly or by extension, would we not be participating in their conflationary character and meaning? Metaphor theory asserts the deeply conceptual nature of such metaphors. Does not the conflation that initiates and founds this account of cognition repeat itself with every use of the primary metaphors, i.e., as we think something abstract as being this or that concrete structure? In short, while metaphor theory acknowledges conflation as one stage in cognitive development, it abandons the notion without explanation. The puzzling presence of conflation in metaphorical cognition is not addressed.

\section{Conflation in Blending Theory}

Blending theory is not tied to any theory of cognitive development or primary metaphor. It locates the work of abstract cognition not in the repetition of preestablished patterns of embodied meaning but in general mental operations which actively construct patterns and "spaces" of meaning. " However, these many operations, the theory asserts, have the overriding goal of achieving blends in buman scale (Fauconnier \& Turner 2002: 312). Again, two key issues arise from this claim.

First, the highly flexible nature of conceptual blending, with its capacities for compressing, expanding, selecting, integrating, unpacking, scaling, and completing semantic domains, makes even conflation seem a weak term. In this respect, where metaphor theory might under-appreciate conflation, seeing cognition instead as a grounded, highly motivated, and constrained process

10 Cf. Lakoff \& Johnson (1998), p. 3. See also Adamson (2004) on the subject of the cognitive unconscious in metaphor theory:

11 Cf. Fauconnier \& Turner (2002), chapter sixteen, "Constitutive and Gwerning Principles". 
rooted in bodily life, blending theory seems almost to revel in the power of thought to manipulate meaning. There is very little, it seems, that cognition is not capable of twisting, conflating, or manipulating to achieve its blends. To avoid an anarchic reading of cognition, then, blending theory must join metaphor theory in exploring the existential, bodily, and phenomenological conditions that guide and constrain cognition, even as it constructs and conflates meanings in novel ways.

Second, in abandoning metaphor theory's claim that primary source domains shape our concepts from the bottom-up, blending theory locates the basic processes that drive cognition in the mental operations of blending. On this view (and supported by many examples), source domains are highly flexible and manipulable by thought. Why, then, we must ask, does cognition insist on building blends at the buman scale? Fauconnier and Turner assert that "a simple human-scale scenario, with a minimal number of agents in a local spatial region and a small temporal interval, is what we are set up to engage with perceptually and behaviorally". (Ibid: 324) But if this is the reason that we seek the human scale, we must admit that there is something necessarily meaningful and compelling about the human scale itself, about patterns at the level of perception and action. Cognition seeks the human scale, we must admit, because meaning dwells there most easily, and because the realm of movement, perception, feeling, and action provides the most natural cognitive setting for meaning to be played out. There is thus an existential component to meaning that precedes and guides cognition towards the human scale. If, then, blending theory is to fully account for the role that various mental operations play in cognition it must include a more robust account of concrete, perceptual meaning as such, since this is the realm of meaning for which the operations perform their work. Such accounts have been a chief concern of many phenomenologists, including Edmund Husserl, Maurice Merleau-Ponty, Edward Casey, Maxine Sheets-Johnstone, David Abrams, and others. Their work provides a good starting point for such an analysis of the existential realm of lived, perceptual meaning.

\section{Addressing Conflation from a Cognitive Perspective}

We have seen that cognitive linguistics has under-theorized the presence of abstract meaning in cognition, emphasizing instead the role of concrete meanings. We have also seen that neither theory under discussion explicitly addresses the conflation of abstract and concrete meanings, which is central to each act 
of metaphorical or blended cognition. In this last section I offer some thoughts on how these issues can be addressed from a cognitive perspective.

Cognition is capable of abstract thinking and is thus not bound to repeat any specific forms or schemas to play out its thinking. But if cognition is capable of thinking about general ideas, then why, as cognitive linguistics has aptly demonstrated, are abstract reflection, theorizing, and philosophizing populated by so many concrete images, patterns, and terms? If, as I have argued, we can no longer deny the capacity for abstract cognition, then we must address the process of conflation by which abstract ideas are made concrete. The key to such an account is to see that abstract domains of meaning are in need of specification. When thinking goes beyond the concrete it loses most of its specific, identifiable character - precisely because it is seeking the most general meaning of an idea. Therefore, when we wish to relate these ideas to the specific issues or situations in our lives, a much more specific form is needed. Simply put, ideas must become specific in order to engage specific problems. This, then, is a basic corollary of the cognitive perspective: the most crucial function concrete forms play in abstract cognition is to bring specification to abstract domains. Abstract cognition is not simply a matter of concrete images determining the nature of our ideas (from below, as it were), since our ideas ultimately transcend each particular form. Nonetheless, when it turns back to engage and inform actual life, abstract cognition borrows much of its specific structure from concrete patterns.

This is perhaps our first clue to the logic of cognitive conflation. The abstract idea requires specification in order to have influence on the specific elements of experience. As was stated above, our abstract ideas play the crucial role of standards or norms for understanding experience. Hence to inform experience, they must take on some specific form within experience; when trying to work out a specific problem, a vague or amorphous norm is no norm at all. Conflation - the overlapping, mixing, and fusing of one meaning with another - serves the crucial need of giving our ideas a specific form with which they can "enter" and engage specific situations.

This point leads to another key thesis of cognitive linguistics, as I read it: meaning is specific, cognition thrives when it has specific meanings to work with. The most specific, specifiable forms of meaning are concrete objects, events, and patterns at the buman scale, and it is at this scale that most of human 
cognition takes place. ${ }^{12}$ The key feature of concrete forms, then, is their specificity. It is because each pattern, e.g., trees, buildings, grasping, spinning, rising, etc. - has a specific way of being that we can identify and "work with" its unique implications and entailments. Specific forms exude meaning at the human scale, the home of meaning.

Now the key act that defines metaphors or blends is thinking about an abstract domain as dwelling in the structure and logic of some particular concrete form. This act of conflation generates meaning because it generates specific implications at the human scale, which can represent implications for the abstract domain, the actual subject matter of thought. Cognitive linguistics has excelled in laying out the mechanics of many metaphors and blends, and it has theorized about the various unconscious, neural, or mental conditions that must be met beneath or behind acts of cognition, but it has neglected to address the logic of conflation that these accounts imply.

I have explored a similar logic in another context, namely, at the level of bodily perception (Adamson 2006). In perceptual experience, we can see that the specific flesh of the body, its actual textures, movements, weight, tensions, etc., provide elements in which the features of external objects can take on specification and meaning. For example, it is through the actual, specific texture of the hands that the specific texture of a rug is known; it is through the actual tensions in the arms that the weight of a child is measured and specified; it is through the actual movements of the body that external motion is gauged. The body, I have argued (following Merleau-Ponty), serves as a sensible standard, a particular element in the perceptual world which lends its concrete flesh to the act of specifying the meaning of other elements. In direct contradiction to classical theories that equate norms, standards, and measures with abstract, intellectual

12 This thesis accords with both metaphor theory and blending theory, but for different reasons. Metaphor theory, in focusing on the embodied, experiential patterns that serves as source domains for abstract cognition, argues that such patterns provide the original and primary locus of meaning. When abstract domains are active in cognition, this theory claims, they are expressed in the specific, human-scale patterns that have already been established as meaningful for us. The body, with its many specific, human-scale schemas, is "in the mind". For blending theory, on the other hand, abstract cognition is much less bound to established patterns of meaning at the concrete level. In many situations, we are confronted with problems that have no clear or recognizable form, and we cannot rely on familiar metaphors or source domains. Thus it is up to us to bring the various aspects of the situation into some recognizable, usable form, and abstract cognition pursues the goal of acbieving meaning at the human scale. A blend is thus a human-scale model of meaning whose elements have been selected, compressed or expanded, integrated, and ultimately conflated to produce a specific, identifiable event or scenario whose properties can be witnessed or played out in thought. 
ideas, we find that it is the particularity of bodily existence, its real, sensible properties, that enable the specific character of other sensible things to emerge.

A similar logic is at work in the conflation we have examined above. The abstract domains of cognition genuinely transcend particular schemas and enable us to question the very schemas we have inherited. However, they can have no bearing on the actual, particular situations we face until they are brought into some specific form that can directly engage the particular elements of the situation. The concrete source domains and mental spaces that cognitive linguistics has analyzed serve the crucial function of speciffing abstract ideas so that they can inform actual situations. These concrete forms are able to specify ideas because they have specific, identifiable properties, ways of being, which can be imaginatively (or in art and ritual, actually) played out at the human scale. But this playing out of abstract meaning in concrete forms is - whether in habitual cognition or conscious problem-solving - always a matter of domain-crossing, distinction-blurring, and messy overlapping - conflation. That this cognitive conflation produces stable, reliable meanings cannot be denied, in light of cognitive linguistics. But the implications of this paradox must be carefully examined.

A central goal of cognitive linguistics, then, should be to examine the logic of conflation at the heart of cognition, in order to bring our theoretical "map" of cognition into closer relationship with the real, lived character of cognitive experience. Central to this task is, on the one hand, a fuller account of abstract domains, which both stand above concrete life and depend deeply on it for its specification, and, on the other hand, an exploration of concrete, human-scale experience, which serves both as the source and goal of cognition.

\section{References}

Abrams, D. (1997). The Spell of the Sensuous: Perception and Language in a More-Than-Human World, New York: Vintage Books.

Adamson, T. (2006). "Measure for Measure: the Reliance of Human Knowledge on the Things of the World". In Ethics and the Entironment. Indianapolis: Indiana L'niversity Press.

Adamson, T. (2005). "Metaphorical Cognition: Two Models". In S. Coulson \& B. Lewandowska-Tomaszczyk (Eds.), The Literal/ Non-Literal Distinction. Editors: Berlin: Peter Lang.

Adamson, T. (2004). "Is Cognitive Linguistics Our Best Phenomenology of Language?: A Philosophical Challenge". In M. Achard \& S. Kemmer (Eds.), Language, Culture and Mind. Palo Alto: The Center for the Study of Language and Information. 
Casey, E. (1993). Getting Back Into Place: Toward a Renewed Understanding of the Place-World. Bloomington: Indiana University Press.

Casey, E. (1997). The Fate Place: A Philosophical History. Berkeley: University of Califomia Press.

Fauconnier, G. \& Turner, M. (2002). The Way We Think: Conceptual Blending and the Mind's Hidden Complexities. New York: Basic Books.

Husserl, E. (1981). Shorter Works. Edited by P. McCormick \& F. Elliston. Notre Dame: Notre Dame University Press.

Johnson, M. (1987). The Body in the Mind. Chicago: University of Chicago Press.

Lakoff, G. \& Johnson, M. (1980). Metaphors We Live By. Chicago: University of Chicago Press.

Lakoff, G. \& Johnson, M. (1998). Philosophy in the Flesh. New York: Basic Books.

Merleau-Ponty, M. (1962). The Phenomenology of Perception. Trans. Colin Smith. London: Routledge \& Kegan Paul.

Merleau-Ponty, M. (1963). The Visible and the Invisible. Trans. Alfonso Lingis. Evanston: Northwestern University Press.

Plato (1971). The Collected Dialogues of Plato, Including the Letters. Ed. by E. Hamilton and H. Cairns. Princeton, NJ: Princeton University Press.

Polanyi, M. (1983). The Tacit Dimension. Gloucester: Peter Smith.

Sheets-Johnstone, M. (1999). The Primacy of Movement. Philadelphia: John Benjamin's.

Weiss, G. (1999). Perspectives on Embodiment: The Intersections of Nature and Culture. New York: Routledge.

Welton, D. (1998). Body and Flesh: A Philosopbical Reader. New York: Blackwell Publishers. 